\title{
Einige Abnormitäten an Bienen
}

\author{
beschrieben von \\ Professor Schenck zu Weilburg (Wiesbaden).
}

1. Ein $\sigma$ von Prosopis (Hylaeus) variegata hat einen schmalen, nicht erweiterten, stark gekrümmten Fühlerschaft; er ist ganz schwarz, so dafs ihm die weifse Erweiterung fehlt.

2. Die Zellenbildung weicht zuweilen bei einzelnen Exemplaren von dem specifischen Charakter $a b$. So hat ein $\delta$ von Andrena Listerella K. (denticulata K. ठ) nur 2 Cubitalzellen durch Verschmelzung der Cubitalzelle 2 und 3, so dafs die Discoidalquerader 1 in Cubitalzelle 2 mündet. Ein $\sigma^{-1}$ und ein $Q$ von Sphecodes ephippius L. und ein $\sigma$ von Sphec. rufiventris Wesm. haben 2 Cubitalzellen durch Verschmelzung der Cubitalzelle 1 und 2, ebenso ein $\sigma^{\top}$ von $S p h$. rufescens Fourcr. Sm., bei welchem aber der rechte Vorderflügel noch eine sehr schmale mittlere Cubitalzelle hat. Bei den vorigen Abnormitäten mündet die Discoidalquerader in die Cubitalzelle 1; dagegen bei einem $\sigma^{\star}$ von Sphecodes ephippius, bei welchem ebenfalls Cubitalzelle 1 und 2 verschmolzen sind, mündet diese Querader in den Anfang der Cubitalzelle 2. Durch Verschmelzung der Cubitalzelle 2 und 3 hat ein Exemplar der Andrena Listerella K. $\sigma$ (denticulata K.) nur zwei Cubitalzellen.

3. Eine Apis mellifica L hat ganz die Gestalt und Gröfse, den Hinterleib, den Rüssel, die Oberkiefer und die Beine eines Arbeiters, aber keine Nebenaugen und statt der 2 Netzaugen nur ein grofses halbmondförmiges auf dem Scheitel, welches sich neben fast bis zur Höhe der Fühlerwurzel hinaberstreckt. Unter diesem Auge ist ein stark behaarter Höcker, dessen unteres Ende sich zwischen den Fühlern befindet. Diese sind länger, als bei den Arbeitern, aber mit kürzerem Schaft; sie haben die Länge der Fühler des $\sigma^{7}$, aber nur 12 Glieder und einen längeren, dickeren Schaft. Der Kopf ist schmäler als der Thorax, kürzer als gewöhnlich, unten weniger verschmälert. Das Segment 6 ist in zwei Theile getheilt und zwischen denselben in der Mitte von oben nach unten eine kahle Haut; das Bauchsegment 6 ragt vor, der Stachel fehlt.' Es ist also offenbar eine Zwitterbildung mit mehrfachen Abnormitäten. 


\section{$2 \mathrm{BHL}$ Biodiversity Heritage Library}

1874. "Einige Abnormitäten an Bienen." Berliner entomologische Zeitschrift / herausgegeben von dem Entomologischen Vereine in Berlin 18(3प4),350-350. https://doi.org/10.1002/mmnd.18740180319.

View This Item Online: $\underline{\text { https://www.biodiversitylibrary.org/item/36410 }}$

DOI: https://doi.org/10.1002/mmnd.18740180319

Permalink: https://www.biodiversitylibrary.org/partpdf/210017

\section{Holding Institution}

Smithsonian Libraries

\section{Sponsored by}

Smithsonian

\section{Copyright \& Reuse}

Copyright Status: Public domain. The BHL considers that this work is no longer under copyright protection.

This document was created from content at the Biodiversity Heritage Library, the world's largest open access digital library for biodiversity literature and archives. Visit BHL at https://www.biodiversitylibrary.org. 